\title{
Why Health-Related Inequalities Matter and which Ones Do
}

\author{
Alex Voorhoeve, LSE \\ Forthcoming in Global Health Priority-Setting: Beyond Cost-Effectiveness. Ed. Ole Frithjof \\ Norheim, Ezekiel Emanuel and Joseph Millum. Oxford University Press.
}

\begin{abstract}
I outline and defend two egalitarian theories, which yield distinctive and, I argue, complementary answers to why health-related inequalities matter: a brute luck egalitarian view, according to which inequalities due to unchosen, differential luck are bad because unfair, and a social egalitarian view, according to which inequalities are bad when and because they undermine people's status as equal citizens. These views identify different objects of egalitarian concern: the brute luck egalitarian view directs attention to healthrelated well-being, while social egalitarianism focuses on health-related capabilities that are central to a person's status as a citizen. I argue that both views are correct and should jointly guide priority-setting in health.
\end{abstract}

\section{Introduction}

Do health-related inequalities matter? Consider the following simple case.

Interpersonal Case: Two ten-year-old children, Aisha and Ben, each have a considerable mobility impairment, which, if untreated, will leave them each with an overall, lifetime well-being level of 40 (a merely okay life). A decision-maker can use their resources to give both children treatment I, which will transform their considerable impairments into moderate impairments with a well-being level of 50 (a 
moderately good life). Or, instead, the decision-maker can produce treatment II, which will be useless for Aisha but will fully cure Ben, ensuring that he has an unqualifiedly good life with a well-being level of $60+d$, with $d$ positive. Table 1 represents this case.

Table 1. Final well-being for the Interpersonal Case

\begin{tabular}{|l|c|c|}
\hline \multirow{2}{*}{ Alternatives } & \multicolumn{2}{|c|}{ Persons } \\
\cline { 2 - 4 } & Aisha & Ben \\
\hline Treatment I & 50 & 50 \\
\hline Treatment II & 40 & $60+d$ \\
\hline
\end{tabular}

What should the decision-maker choose? To many (myself included), it is clear that if $d$ is sufficiently small (but positive), it would be unjustifiable for the decision-maker to choose II (Nord and Johansen 2014). After all, doing so would leave Aisha much worse off than Ben for only a modest gain in aggregate well-being.

This judgment is, of course, inconsistent with utilitarianism, which holds that, in a given population, one ought to maximize expected total well-being. It is also inconsistent with using only the standard measure of cost-effectiveness to set priorities, according to which an increment of a given size in health-related well-being is just as valuable no matter whether it comes to a badly off person or instead to a different, better-off person. This judgment therefore motivates the search for an alternative account of distributive justice and concomitant alternative principles for priority setting in health. 
In this chapter, I outline and defend two egalitarian theories: a brute luck egalitarian view, according to which inequalities due to unchosen, differential luck are bad because unfair, and a social egalitarian view, according to which inequalities are bad when and because they undermine people's status as equal citizens. These views, I will argue, yield distinctive and complementary answers to why health-related inequalities matter. Moreover, they identify different objects of egalitarian concern: the brute luck egalitarian view I articulate is occupied with health-related well-being, conceived of as how well a person's life goes from a selfinterested perspective, while social egalitarianism cares about specific health-related capabilities that are central to a person's status as a citizen. I will argue that each view identifies an important component of distributive justice in health, so that they should jointly guide priority-setting.

I proceed as follows. In section 1 , I describe and justify a brute luck egalitarian view. In section 2, I do so for a social egalitarian view. In section 3, I explain why we should endorse both. Throughout, I trace some implications of these egalitarian views for both national and global priority-setting in health.

\section{A brute luck egalitarian view}

Brute luck egalitarians hold that, other things equal, it is in itself bad, because unfair, if some people fare less well than others due to mere luck. They also believe that inequalities need not be bad or unfair if they reflect choices for which people can be held responsible (Temkin 2013).

Though brute luck egalitarians differ in their conception of the currency of distributive justice, I shall here discuss a version of brute luck egalitarianism which takes this currency to be lifetime prudential value, or well-being, understood as how well a person's life as a whole 
goes, considering only their self-interest. (In this, I follow Lippert-Rasmussen [2015, p. 156].

I shall offer reasons for taking the object of egalitarian concern to be lifetime well-being in Section 3.)

On this form of brute luck egalitarianism, health typically matters a great deal, both because it is partly constitutive of well-being and because it is instrumental to other components of well-being, such as a person's income and education. But health matters only insofar as it contributes to well-being in these ways.

Brute luck egalitarianism, so conceived, is only one part of distributive justice. For this principle doesn't explain why it is better when everyone is equally well off than when everyone is equally badly off (Parfit 1995). One must therefore supplement it with a principle according to which it is in itself better if people have more valuable life prospects.

Such a pluralist brute luck egalitarian view explains our judgment in the opening Interpersonal Case. For a small $d$, it regards treatment I as the right choice, because it ensures equality at little cost in total well-being, whereas treatment II would generate substantial inequality with only small gains in total well-being.

A concern for unfairness does not merely motivate an aversion to unequal outcomes; it also motivates an aversion to unequal prospects. Suppose, for example, that two equally-situated patients urgently need a transplant kidney to survive. Suppose further that only one kidney is available, so that one patient will live while the other will die. There is less unfairness if each is granted an equal chance of receiving the kidney (Broome 1990).

While the sentiments that underlie pluralist egalitarianism are, I submit, both recognizable and appealing, some have argued as follows against the egalitarian concern for fairness (see, for example, Parfit 1995, 17-18). 
Suppose that, in our kidney case, no transplant kidney is available, so that both will die. In this scenario, there is no unfair inequality between these patients. Pluralist brute luck egalitarianism is therefore committed to the claim that while it is in one way worse if both patients die (because of the loss in well-being) it is also in one way better, because there is no longer unfair inequality between these patients. However, there is nothing good in such levelling down. This form of egalitarianism is therefore false.

I submit that this so-called "levelling-down objection" to egalitarianism has no force. For it seems right that two factors - a concern for well-being and for comparative fairness - jointly determine our judgment in this and other distributive cases. On balance, any sensible pluralist egalitarian will hold that it is clearly morally better that the world is like the first, unequal scenario, in which one lives and one dies, than like the latter, equal scenario, in which both die, because it is better that at least one person's life is saved, even at the cost of some unfairness. But it is also nonetheless clear that the first, unequal situation involves some unfairness between the two individuals, whereas the latter does not. To further illustrate the naturalness of this dual concern for improving well-being and reducing unfairness, imagine that one is initially in the first scenario with only one kidney, and one then learns that, in fact, two transplant kidneys are available, so that both patients will be saved. It would, I submit, be commonplace to see this development as good both because it improves someone's life and because it removes the initial unfairness of saving only one of two people who each had equal claims to life-saving treatment.

In further defense of this form of egalitarianism, I shall now argue that its dual concerns enable it to meet a central requirement of a theory of distributive justice, which is to appropriately respond to the fact that a single person's life possesses a unity which a mere collection of people lacks (Rawls 1999, 23-4). 
To explain this idea, I will consider a case involving risk. This example requires further assumptions about our measure of health-related well-being. I shall assume an idealized version of what is known in health economics as the "standard gamble" (Dolan 2001). On this measure, which conforms to orthodox decision theory, a first alternative has higher expected well-being for a person than a second alternative just in case the first would be strictly preferred after rational, calm deliberation with all pertinent information while considering their self-interest only. Two alternatives yield equal expected well-being just in case such deliberation would yield indifference between them.

Now consider the following:

Intrapersonal Case (Otsuka and Voorhoeve 2009): Suppose a ten year-old child, Chia, has the aforementioned considerable mobility impairment, which, if untreated, will leave her with a lifetime well-being of 40. A decision-maker can provide only one of the following treatments. Treatment I will transform this considerable impairment into a moderate impairment and thereby raise Chia's well-being to 50 . Treatment II is riskier: with 50 percent probability, it will leave her considerable impairment unchanged and with 50 percent probability, it will offer a full cure, leading to a health-related well-being of $60+d$, with $d$ positive. This case is represented in Table 2, in which S1 and S2 represent possible states of the world, and the numbers in brackets indicate the probability that they will occur. 
Table 2. Final well-being for the Intrapersonal Case

\begin{tabular}{|l|c|c|}
\hline \multirow{2}{*}{} & \multicolumn{2}{|c|}{ Possible states of the world } \\
\cline { 2 - 3 } & S1 (0.5) & S2 $(0.5)$ \\
\cline { 2 - 3 } Alternatives & Chia & Chia \\
\hline \multirow{2}{*}{ Treatment I } & 50 & 50 \\
\hline Treatment II & 40 & $60+d$ \\
\hline
\end{tabular}

Treatment II uniquely maximizes Chia's expected well-being. Given the measure of wellbeing assumed above, a decision-maker can offer her the following justification for choosing II:

"In making this choice, I had to balance a 50 percent chance of leaving you with the considerable impairment rather than with the moderate impairment against a 50 percent chance of you being fully healthy rather than moderately impaired. I balanced this potential benefit foregone and potential additional benefit from the perspective of your self-interest alone. From this perspective, the value of the chance of the additional benefit outweighed the value of the chance that you would not receive any benefit. I therefore chose treatment II. In so doing, I did the best I could do for you, given the information available at the time."

The availability of this prudential justification gives the decision-maker a good reason to choose treatment II for any positive $d$. Moreover, when such a decision-maker considers 
Chia's prospects in isolation from how anyone else fares, they have no reason to do otherwise (Otsuka 2015). I conclude that, insofar as only her prospects are considered, the decisionmaker should choose treatment II. The pluralist brute luck egalitarian view I have outlined concurs. For in this case, inequality is not an issue. The egalitarian part of this view is therefore silent. This leaves the decision to the other principle, which commands the improvement of people's prospects and therefore selects II.

Note that this Intrapersonal Case involves the same increments in well-being, and from the same levels, as our opening Interpersonal Case. In both cases, the choice between treatments I and II involves balancing the importance of improving one person from 40 to 50 against the importance of improving one person from 50 to $60+d$. The crucial differences are, of course, these. In the Interpersonal Case, one must balance an improvement from 40 to 50 for Aisha, an improvement that would make her as well off as another person, against an improvement from 50 to $60+d$ for a different person that would also make that person much better off than Aisha. By contrast, in the Intrapersonal Case, one must balance an improvement from 40 to 50 in one possible future of Chia's against an improvement from 50 to $60+d$ in another possible future of the same person; moreover, inequality is not an issue. These differences affect the moral considerations that are relevant to making these trade-offs. In the Intrapersonal Case, if the decision-maker chooses II and things turn out badly for Chia, they can say that while they are unhappy with the outcome, they acted only for Chia's sake. By contrast, in the Interpersonal Case, no such prudential justification is available to Aisha if the decision-maker were to choose II. Instead, all the decision-maker could say to her is that they decided to forgo a substantial improvement in her well-being in order to offer a somewhat greater benefit to someone else (Ben), thereby ensuring that she will be worse off than this other person. These differences make II much harder to justify in the Interpersonal Case than in the Intrapersonal Case. In the Intrapersonal Case, it is permissible to choose II for any 
positive $d$. But in the Interpersonal Case, for a sufficiently small, positive $d$, it is impermissible to choose II.

As we have seen, pluralist brute luck egalitarianism accounts for this shift in the weight one should assign to increments in well-being. In this, it aligns with people's moral sensibilities. Surveys reveal that a majority of subjects give greater weight to improving one person from a considerable to a moderate impairment when this must be balanced against improving a different person from a moderate impairment to full health, as in our Interpersonal Case, than when a chance of improving someone from a considerable to a moderate impairment must be balanced against an equal chance of improving the same person from a moderate impairment to full health, as in our Intrapersonal Case (Nord and Johansen 2014). Following the so-called "method of reflective equilibrium," on which one of the aims of moral theory is to find principles that offer the best explanation of confidently held case judgments (Rawls 1999), this fit with widely held judgments should raise our confidence in pluralist brute luck egalitarianism.

We can conclude that the form of brute luck egalitarianism sketched here satisfies a foundational requirement of distributive justice, that is, respect for both the unity of the individual (which gives us reason to make intrapersonal trade-offs as prudence dictates) and the separateness of persons (which, when people's interest conflict, requires that we give greater weight to the interests of those who are worse off than others) (cf. Voorhoeve and Fleurbaey 2016).

The proposed view is compatible with a priority-setting process that is guided by at least two values: improving aggregate population health-related well-being (in a population of a given size) and reducing unfair inequality (Norheim et al. this volume). At the national level, an example is the proposal by the Norwegian Committee on Priority Setting in the Health Sector, which operationalizes these aims through an equity-sensitive cost-effectiveness 
threshold, on which an additional healthy life-year for those Norwegians who have low lifetime health-related well-being is allowed to cost up to three times more than an additional healthy life-year for those who have high lifetime health-related well-being (Ottersen et al. 2016; cf. Lauer, Bertram, and Morton this volume). The former is worth more, it holds, because it advances both the aim of raising total well-being and the aim of reducing inequality. This system therefore assigns special importance to interventions that improve conditions that often strike people down in their youth, such as bacterial meningitis, or that cause lifelong, substantial losses of functioning, such as multiple sclerosis.

Another example of national priority setting informed by this form of egalitarianism is offered by the proposals of the WHO Consultative Group on Equity and Universal Health Coverage (WHO 2014). These state that in setting priorities, extra weight should be given to the needs of those who are disadvantaged along a variety of dimensions that impact wellbeing, including health prospects, health outcomes, income, and social status. Unlike the Norwegian Committee, this group does not propose a single formula for assigning additional weight to the interests of the worse off. Instead, in a series of case studies in within-country priority-setting, some of its members advocate context-specific deliberation about how inequality along a variety of dimensions should influence decision-making (Voorhoeve et al. 2016; 2017).

Brute luck egalitarianism also has marked implications for the global allocation of resources for health. For it holds that unchosen inequality between any people, at any time and any place, is unfair (Beitz 1975; Segall 2016). And the current distribution of health expenditure across the globe is most likely seriously at odds with what this cosmopolitan theory requires. For example, in 2014, annual per capita health expenditure in current USD in some of the richest countries, including Norway, Switzerland and the USA, stood at just below USD 10,000 per person, well over three hundred times the annual per capita health expenditure in 
some of the poorest nations, including Madagascar, Ethiopia, and Malawi (World Bank 2017). Estimates suggest that, at least at the margin, directing greater health-care resources towards improving the health of the globally poorest has the potential to greatly improve their health-related quality of life at a cost per unit of health-related well-being gained that is considerably below that of marginal health expenditure in the richest countries (see, e.g. Horton et al. 2017; WHO-CHOICE 2017). If these estimates are correct and would hold not merely for comparatively small marginal increases but also for large increases in resources, then this form of egalitarianism demands a large increase in assistance by better-off countries and well-off individuals to promote the health of the globally worst off (see, e.g. Røttingen et al. 2014). In allocating this assistance, the view implies high priority for measures that effectively combat the causes of death and lifelong impairments to young persons in the poorest nations. Examples are skilled birth attendance, bed nets and prophylaxis for malaria, and improvements in traffic safety (WHO 2014, p. 16).

\section{A social egalitarian view}

In addition to how people fare compared to others in terms of lifetime well-being, it is also important to note how they interact with and relate to each other. The form of brute luck egalitarianism I have outlined considers these issues only insofar as they affect people's wellbeing. But, as I will now discuss, their relationships and attitudes matter for further reasons.

The view I refer to as "social egalitarianism," and which is also sometimes referred to as "democratic egalitarianism," comes in different versions (Fourie et al. 2015). The version I consider here starts from the idea that normal adult citizens possess what Rawls (1999, sec. 77) called "two moral powers." The first moral power is the ability to freely form, revise and pursue a conception of a good life. The second is a sense of justice. This includes the ability 
to propose and deliberate about fair terms of social co-operation. It also includes the motivation to abide by these terms when there is assurance that others will do so too. Social egalitarianism holds that one should promote and respect the free development and use of these capacities, and that this requires establishing a society in which all competent adults are granted the status of equal citizen. This status can be lost only through criminal acts or when it is freely renounced, say, when a person takes citizenship elsewhere (Anderson 1999). (For simplicity, I will here consider nationals only.) This status of equal citizen is multifaceted. Among its requirements is that each is capable of participating in public life with dignity and independence. It also demands that all citizens have the same rights to contribute to public deliberation and governance and that their interests are in fact weighed equally in public decision-making (Scheffler 2015). Additionally, it asks that people develop a set of moral attitudes towards themselves and fellow citizens. These include a sense of their worth, sympathy with co-citizens, a preparedness to together develop mutually advantageous and fair institutions, and a willingness, in public interactions, to treat each person with the respect due to them as a citizen and judge them by their character and actions rather than by such things as class membership, skin color, or religion.

In a social egalitarian society, citizens have the rights, resources, and attitudes required to freely develop the aforementioned two moral powers and to act as equals in the public sphere. They are then in a position to establish a community in which the distribution of benefits and burdens and the exercise of political power take place in accordance with rules that each can accept as reasonable (Rawls 1999, sec. 1; 2005 lec. 1; Daniels 2003). On this view, inequalities are bad when and because they cause society to fall short of this ideal. I will now draw on four aims that social egalitarians have formulated for social policy to explain how this view can inform priority setting in health. 
(i) Avoiding domination and exploitation in private life (Anderson 1999). This aim gives us reason to avoid health states that impair adults' ability to stand up for themselves, because, say, they have come to depend for assistance on the good will of more powerful persons who, in their actions towards them, are neither guided by secure bonds of affection (as family members often are) nor constrained by well-enforced standards of care. It also gives us reason to arrange care in a manner that empowers patients. Moreover, it favors pre-payment for health costs through insurance or taxation over out-of-pocket payment. For such pre-payment systems allow people to access reasonable and needed care without falling into grave financial distress. They thereby make people less vulnerable to exploitation.

(ii) Avoiding political domination and marginalization (Anderson 1999). This aim gives us reason to prevent and alleviate health states that present obstacles to people having their voices heard in politics and civil society. (Examples are considerable impairments in mobility, in communication, or in cognitive and emotional functioning.)

(iii) Securing the bases of self-respect. As Rawls (1999) put it, self-respect is usually a precondition for success in one's goals and for contributing confidently to public discussion about proper terms of social cooperation. It follows that we have reason to sustain capacities central to people's sense of self-worth, such as the capacity to wash and dress oneself and move about unaided, and the capacity to manage one's affairs. This aim also gives us reason to alleviate health conditions that generate a debilitating sense of shame or inadequacy, such as disfigurements. In addition, it motivates an aversion to inequalities in health and wealth when 
these give rise to norms of appearance and functioning that the less well-off cannot meet.

(iv) Sustaining the attitudes required for a sense of community. Large inequalities in health and income can generate a sense of inferiority among the least well off and of superiority among the best off, who can come to believe that they do not owe the less fortunate an explanation for their common institutions (Tawney 1964, 378). Such inequalities may also cause the most severely disadvantaged to form the envious wish that the prospects of the most fortunate are worsened, even if this would do nothing to ameliorate their own situation. In response, the fortunate may become willing to incur substantial costs simply to remain relatively advantaged (Rawls 1999, 467-8). Social co-operation is undermined by these attitudes. The aim of maintaining such co-operation therefore gives us reason to avoid extreme gaps in health and financial resources between the best-off and worst-off and to develop institutions which are widely understood to promote shared interests.

These concerns notwithstanding, social egalitarianism does not regard every health-related inequality as problematic, since some such inequalities are consistent with a society in which people can interact as equals. In general, its aversion to particular inequalities is therefore contingent on empirical information about how these inequalities impact on the status, relationships, and attitudes it regards as valuable. However, it does invariably object to health-related inequalities that are due to lack of equal consideration of relevant interests (e.g. because of discrimination). These offend social equality because their existence is a consequence of a failure to live up to its ideals. In priority setting in health, social egalitarians will therefore give additional weight to those whose disadvantage is due to past improper consideration of their interests (Braveman et al. 2011). Moreover, social egalitarianism's focus on securing equal standing makes it wary of health-related disadvantages that are 
correlated with membership in socially salient, disadvantaged groups (e.g., ethnicities that also face worse economic opportunities). Such correlated inequalities may be especially threatening to social co-operation, since they risk establishing or perpetuating some people's status as second-class citizens (Braveman et al. 2011).

\section{A social-and-brute-luck-egalitarian view}

Some have argued that social and brute luck egalitarianism are opposing views (Anderson 1999). By contrast, I submit that there are good reasons to be both a social and a brute luck egalitarian (cf. Brown 2005; Bidadanure 2016). Each of these views has a compelling basis. Moreover, as I have formulated them here, they are complementary, in the sense that each helps fill a lacuna in the other. Brute luck egalitarianism, as I have defined it, says only that inequalities that are unrelated to choices for which people can be held responsible are unfair; to complete their theory, brute luck egalitarians therefore require further principles to regulate choice-based inequalities. Social egalitarianism offers one such principle: it specifies that one has reason to be averse to choice-based inequalities that threaten people's status as equal citizens and social cohesion. Meanwhile, social egalitarianism has its own lacunae. One of its central principles is that public decision-making should consider the interests of each equally (Scheffler 2015). But this principle is in need of further specification. After all, many different distributive theories, including utilitarianism, claim to embody such equal consideration. The arguments of section 1 make a strong case for pluralist brute luck egalitarianism as an interpretation of equal consideration. Another lacuna in social egalitarianism is that it says nothing about inequalities between people who do not share the same social institutions and who do not exercise power over each other. But such silence is unwarranted. If, due to the misfortune of having few natural resources, members of one autarkic society were much less well-off than the members of another better-endowed 
society, this inequality would be morally objectionable and call for remedy (Beitz 1975).

Such scenarios illustrate why social egalitarianism needs supplementation.

Another sense in which these views are complementary is that social egalitarianism directs our attention to a precondition for the realization of pluralist brute luck egalitarian distributive justice, namely, the willingness of each citizen to search for and abide by fair terms of social co-operation. For example, a solidaristic system of mandatory health insurance in which the rich and healthy subsidize the poor and unhealthy can function only if fortunate citizens support the necessary transfers. Social egalitarianism is, in part, about establishing the conditions that make it likely that they will do so.

The two forms of egalitarianism will agree on some issues in priority setting in health. An example is the prevention and treatment of infections with intestinal worms (soil-transmitted helminths). Among the effects on children of such worms is worse nutritional status with concomitant effects on growth and development, as well as poorer performance at school (WHO 2016). Such infections therefore affect both lifetime well-being and the capacities required for citizenship. Moreover, their prevalence is highest in areas with poor sanitation, which means that they disproportionately affect the nationally and globally worst-off (WHO 2016), who are also more likely to be dominated and marginalized. Both brute luck egalitarianism and social egalitarianism therefore give us reason to prioritize interventions that counter intestinal worms.

There are, nonetheless, differences between the two forms of egalitarianism. One pertains to their objects of egalitarian concern. As mentioned in Section 1, for the brute luck egalitarian, this object is here taken to be how people fare compared to others over the entire period in which they remain the same person in a relevant sense. (Barring a severe deterioration of cognitive functioning, this period encompasses at least the time from when they are a schoolaged child until death.) This contrasts with a view which concerns itself with how a person's 
well-being in a given time period compares to others' well-being in that time period. One reason for the plausibility of an exclusively lifetime view is that it allows for the intrapersonal compensation of burdens at one time by later benefits. The possibility of such compensation is an aspect of the unity of the individual's life highlighted in Section 1. It is embodied in our practices of imposing burdens for the sake of later, larger benefits such as having a ten-year-old undergo a painful operation for the sake of greater advantages that will accrue to them as an adult. It also yields appealing case judgments. By way of illustration, consider the following case:

Lifetime Equality, within-period Inequality Case: Danielle and Ebo will be alive at the same time for two equally long periods. Each person's lifetime well-being is the sum of their well-being across these periods. Unless the decision-maker acts, in period 1, Danielle will have a considerable mobility impairment and a within-period wellbeing of 20, while Ebo will have a moderate mobility impairment, which yields a within-period well-being of 25. In period 2, Danielle will be almost fully cured of her impairment, yielding her a within-period well-being of 30, while Ebo will retain his moderate mobility impairment, yielding a within-period well-being of 25 . Their impairments do not hinder them in capacities that are central to their situation as equal citizens. The decision-maker can improve their fate by distributing among them benefits that will accrue to them in period 2. The total benefit is two units of wellbeing (its total size does not depend on how it is distributed). They must either give each of Danielle and Ebo one additional unit of well-being or give Danielle somewhat less and Ebo somewhat more than one unit.

On a lifetime egalitarian view, Danielle's comparative misfortune in period 1 will be perfectly compensated by her comparative good fortune in period 2, so that she will be, overall, neither more nor less fortunate than Ebo; without the decision-maker's intervention, each will have a 
lifetime well-being of 50. On this view, therefore, at every point in time, both Danielle and Ebo have an equally strong claim to an extra unit of well-being; the decision-maker should therefore divide the available benefit equally. By contrast, a view concerned with equality of condition within each time period would register objectionable inequality in both periods. To mitigate the inequality in period 2, it would assign Ebo a greater claim to a benefit in period 2, implying the decision-maker should give him a somewhat larger than equal share of the available benefits. I submit that the lifetime view's judgment in this case is correct.

By contrast, the social egalitarian is, at least in part, concerned with social equality at each point in time. Domination and marginalization are evils whenever they occur, even if those who are dominated or marginalized in one period later turn the tables on those who previously lorded it over them (Bidadanure 2016). We can illustrate this view's implications by adjusting the just-mentioned case. Suppose that, contrary to our initial supposition, in period 1, Danielle was more likely to be in an inferior social position than Ebo because of her more severe impairment in that period, while Ebo was more likely to be so in period 2. Then a social egalitarian would prioritize measures to alleviate the impact of Danielle's impairment on her standing and ability to participate in social life in period 1, while prioritizing improvements in Ebo's standing and participatory capabilities in period 2.

It is also worth noting that social egalitarianism implies that particular health-related capabilities - e.g., to be free from domination, to participate with dignity in social life — have an importance that may differ from the importance that individuals assign to these capabilities from a self-interested perspective (Hausman 2015, chap. 13). By way of illustration, imagine a shy person who enjoys playing the piano at home. If this individual suffers from both a speech impediment and tendonitis, they may reasonably regard a cure for their tendonitis as more important to them than a cure for their speech impediment, because the former will enable them to resume their hobby. Social egalitarianism, however, may well 
hold that from a public perspective, the relative importance of curing these two ailments is the inverse of what is it from this person's personal perspective, because the speech impediment is a greater barrier to their functioning as a citizen.

These differences in the objects of distributive concern between our two egalitarian views may lead them to prioritize interventions differently. For example, a brute luck egalitarian may assign relatively low weight to a given increment in health-related well-being for someone who is at risk of a mild to moderately severe stroke late in life, since this would affect people who generally have had relatively high lifetime health-related well-being. Indeed, in the Norwegian proposal mentioned at the end of section 2, one extra healthy lifeyear for such a patient would receive only one-third of the weight of an extra healthy life-year for a patient with multiple sclerosis, because the latter typically has far lower lifetime healthrelated well-being (Ottersen et al. 2016). By contrast, from a social egalitarian perspective, preventing deterioration in cognitive function and mobility due to strokes in elderly people may be of great importance, since they preserve capacities for deliberation, self-governance and self-care.

Another point of tension between these views arises from their scope. Social egalitarianism is naturally interpreted as assigning a decision-maker special responsibility for ensuring that they (and/or the collective agent in whose name they act) are not engaged in domination and exploitation and that the members of their political communities possess the attitudes constitutive of egalitarian social cooperation. So understood, it is likely to require that a decision-maker assigns greater importance to ensuring that their co-nationals acquire the relevant capabilities and attitudes than to assisting those among the global poor with whom the decision-maker does not stand in a problematic relationship. Of course, social egalitarianism will condemn global inequalities when they are the upshot of, or reinforce, global power structures in which the less well-off are dominated or marginalized (Sanyal 
2012). However, its concerns contrast with the form of brute luck egalitarianism outlined here, which is as troubled by unchosen inequalities between co-nationals as it is by such inequalities between people in different nations. This difference is likely to lead to divergent priorities: brute luck egalitarianism arguably motivates a greater focus on reducing global inequalities in health-related well-being, while social egalitarianism's concern with ending relationships of domination, exploitation, and marginalization seems to justify a greater focus on reducing domestic health-related inequalities. Of course, these contrasts do not demonstrate that the views are incompatible — only that the different components of justice may place competing demands on us.

In national and global priority setting, there is, then, a need to consider the multiple values outlined here- improving total health-related well-being, reducing brute luck inequality, and securing the bases of social co-operation among equals. In the light of value pluralism and the diverse objects of distributive importance, an equity-sensitive cost-effectiveness criterion that considers only life-time health-related well-being should be only one input into a prioritysetting procedure. This procedure should also systematically consider interventions' impacts on people's functioning as citizens and their attitudes towards themselves and others. The relevant values are difficult to balance against each other; moreover, the quality of the information available on the interventions' impact will often be limited. Priority setting will therefore always require deliberation and educated judgment (Voorhoeve et al. 2017). What is crucial, however, is that mechanisms are put in place to ensure that the diverse egalitarian values outlined here are always taken into account. 


\section{Conclusion}

I have argued that there are many reasons to care about inequality and that these reasons direct us to attend to inequalities along various dimensions. As pluralist brute luck egalitarians emphasize, we should give special weight to improvements in the well-being of the less well-off, for example, by targeting health conditions that cut short people's lives in their youth or that occur among the poor. As social egalitarians emphasize, we should secure people's capacity to join in social and political life as equal citizens, with dignity and independence. This requires special attention to particular conditions, including those that affect central cognitive capacities, capacities for self-care and the ability to partake in social life without shame. These views are, I have argued, both well-founded. Pluralist brute luck egalitarianism is rooted in a concern for improving well-being and for its fair distribution, as well as in respect for both the unity of the individual and the separateness of persons. Social egalitarianism is grounded in our capacity to govern ourselves and our ability to join with others to deliberate about, establish, and maintain fair terms of co-operation. These forms of egalitarianism accordingly embody some of our most important values. In setting priorities in health, we should therefore be guided by both of them.

\section{Acknowledgements}

I am grateful to Ezekiel Emmanuel, Joseph Mazor, Ole Frithjof Norheim, Trygve Ottersen and two anonymous referees for comments and to the Department of Bioethics of the National Institutes of Health for a Visiting Scholarship, during which this piece was written. The opinions expressed are the view of the author. They do not represent any position or policy of the U.S. National Institutes of Health, the Public Health Service, or the Department of Health and Human Services. 


\section{References}

Anderson, Elizabeth. 1999. "What Is the Point of Equality?” Ethics 109: 287-337.

Beitz, Charles. 1975. "Justice and International Relations." Philosophy and Public Affairs 4: $360-89$.

Bidadanure, Juliana. 2016. "Making Sense of Age-Group Justice: A Time for Relational Equality?” Politics, Philosophy \& Economics 15(3): 234-60.

Braveman, Paula, Shiriki Kumanyika, Jonathan Fielding, Thomas LaVeist, Luisa N. Borrell, Ron Manderscheid, and Adewale Troutman. 2011. "Health Disparities and Health Equity: The Issue Is Justice.” American Journal of Public Health 101: S149-55.

Broome, John. 1990. "Fairness.” Proceedings of the Aristotelian Society 91: 87-101.

Brown, Alexander. 2005. "Luck Egalitarianism and Democratic Equality." Ethical Perspectives 12: 293-340.

Daniels, Norman. 2003. “Democratic Equality: Rawls's Complex Egalitarianism.” In The Cambridge Companion to Rawls, edited by Samuel Freeman, 241-76. Cambridge: Cambridge University Press.

Dolan, Paul. 2001. "Output Measures and Valuation in Health.” In Economic Evaluation in Health Care, edited by Michael Drummond and Alistair McGuire, 46-67. Oxford: Oxford University Press.

Fourie, Carina, Fabian Schuppert, and Ivo Wallimann-Helmer, editors. 2015. Social Equality: On What It Means to Be Equals. New York: Oxford University Press.

Hausman, Daniel. 2015. Valuing Health: Well-Being, Freedom and Suffering. Oxford: Oxford University Press. 
Horton, Susan, Hellen Gelband, Dean Jamison, Carol Levin, Rachel Nugent, and David Watkins. 2017. "Ranking 93 Health Interventions for Low- and Middle-Income Countries by Cost-Effectiveness.” PLOS ONE 12(8): e0182951.

Lauer, Jeremy, Melanie Bertram, and Alec Morton. 2018. “Cost-Effectiveness Analysis.” In Global Health Priority Setting: Cost-Effectiveness and Beyond, edited by Ole Frithjof Norheim, Ezekiel Emanuel, and Joseph Millum, chapter 4. New York: Oxford University Press.

Lippert-Rasmussen, Kasper. 2015. Luck Egalitarianism. London: Bloomsbury.

Nord, Erik, and Rune Johansen. 2014. "Concerns for Severity in Priority Setting in Health Care: A Review of Trade-off Data in Preference Studies and Implications for Societal Willingness to Pay for a QALY.” Health Policy 116: 281-8.

Norheim, Ole Frithjof, Mieraf Taddesse, Solomon Memirie, Kjell Arne Johansson, and Trygve Ottersen. 2018. "Incorporating Distributional Concerns into CostEffectiveness Analysis.” In Global Health Priority Setting: Cost-Effectiveness and Beyond, edited by Ole Frithjof Norheim, Ezekiel Emanuel, and Joseph Millum, chapter 10. New York: Oxford University Press.

Otsuka, Michael, and Alex Voorhoeve. 2009. "Why It Matters that Some Are Worse Off than Others: An Argument against the Priority View.” Philosophy and Public Affairs 37: 171-99.

Otsuka, Michael. 2015. "Prioritarianism and the Measure of Utility." Journal of Political Philosophy 23: 1-22.

Ottersen, Trygve, Reidun Førde, Meetali Kakad, Alice Kjellevold, Hans Olav Melberg, Atle Moen, Ånen Ringard, and Ole Frithjof Norheim. 2016. “A New Proposal for Priority Setting in Norway: Open and Fair." Health Policy 120: 246-51. 
Parfit, Derek. 1995. “Equality or Priority?” The Lindley Lecture. The University of Kansas.

Rawls, John. 1999. A Theory of Justice, revised $2^{\text {nd }}$ edition. Oxford: Oxford University Press.

Rawls, John. 2005. Political Liberalism, expanded edition. New York: Columbia University Press.

Røttingen, John-Arne, Trygve Ottersen, Awo Ablo, Dyna Arhin-Tenkorang, Christoph Benn, Riku Elovainio, David B. Evans, Luiz Eduardo Fonseca, Julio Frenk, David McCoy, Di McIntyre, Suerie Moon, Gorik Ooms, Toomas Palu, Sujatha Rao, Devi Sridhar, Jeanette Vega, Suwit Wibulpolprasert, Simon Wright, Boon-Min Yang. 2014. Shared Responsibilities for Health. A Coherent Global Framework for Health Financing. London: Chatham House.

Sanyal, Sagar. 2012. “A Defense of Democratic Egalitarianism,” Journal of Philosophy 109: $413-34$.

Scheffler, Samuel. 2015. “The Practice of Equality.” In Social Equality: On What It Means to Be Equals, edited by Carina Fourie, Fabian Schuppert, and Ivo Wallimann-Helmer, 21-44. New York: Oxford University Press.

Segall, Shlomi. 2016. Why Inequality Matters: Luck Egalitarianism, Its Meaning, and Value. Cambridge: Cambridge University Press.

Tawney, Richard. 1964. Equality (5th edition). London: Unwin.

Temkin, Larry. 2013. “Inequality and Health.” In Inequalities in Health: Concepts, Measures, and Ethics, edited by Nir Eyal, Samia Hurst, Ole Frithjof Norheim, and Daniel Wikler, 13-26. Oxford: Oxford University Press.

Voorhoeve, Alex and Marc Fleurbaey. 2016. "Priority or Equality for Possible People?" Ethics 126: 929-54. 
Voorhoeve, Alex, Tessa T.-T. Edejer, Lydia Kapiriri, Ole Frithjof Norheim, James Snowden, Olivier Basenya, Dorjsuren Bayarsaikhan, Ikram Chentaf, Nir Eyal, Amanda Folsom, Rozita Halina Tun Hussein, Cristian Morales, Florian Ostmann, Trygve Ottersen, Phusit Prakongsai, Carla Saenz, Karima Saleh, Angkana Sommanustweechai, Daniel Wikler, and Afisah Zakariah. 2016. "Three Case Studies in Making Fair Choices on the Path to Universal Health Coverage." Health and Human Rights Journal 11(2): $11-22$.

Voorhoeve, Alex, Tessa T.-T. Edejer, Lydia Kapiriri, Ole Frithjof Norheim, James Snowden, Olivier Basenya, Dorjsuren Bayarsaikhan, Ikram Chentaf, Nir Eyal, Amanda Folsom, Rozita Halina Tun Hussein, Cristian Morales, Florian Ostmann, Trygve Ottersen, Phusit Prakongsai, Carla Saenz, Karima Saleh, Angkana Sommanustweechai, Daniel Wikler, and Afisah Zakariah. 2017. "Making Fair Choices on the Path to Universal Health Coverage: Applying Principles to Difficult Cases.” Health Systems and Reform 3(4): 1-12.

WHO. 2014. Making Fair Choices on the Path to Universal Health Coverage. Geneva: World Health Organization.

WHO. 2016. Intestinal Worms. http://www.who.int/intestinal_worms/disease/en/ Accessed September 21, 2016.

WHO-CHOICE. 2017. Cost-Effectiveness Results. http://www.who.int/choice/costeffectiveness/results/en/ Accessed November 21, 2017.

World Bank. 2017. World Development Indicators. http://databank.worldbank.org/data/ Accessed November 20, 2017. 